\title{
Journal Programs and Cross-Disciplinary Research
}

\author{
Marianne A. Reed \\ Digital Initiatives Manager \\ University of Kansas Libraries \\ mreed@ku.edu \\ https://orcid.org/0000-0001-8452-6103
}

I

n the late 1990s, as the cost of commercially-published journal subscriptions increased and library budgets held steady or declined, university libraries began to explore ways to change the scholarly publishing ecosystem through initiatives designed to shift control of academic publishing from commercial entities back to the academic community. ${ }^{1}$ One strategy employed was the creation of library publishing programs that supported faculty in the publication of quality open access journals that made peer-reviewed scholarly research freely available to anyone in the world with a computer and an Internet connection. Since they were not driven by profit, library journal programs could publish cross-disciplinary research that had scholarly merit, but was not considered viable by commercial publishers. These programs provided universities with new opportunities to showcase the research of their faculty and to make it available to a worldwide audience. ${ }^{2}$

In 1998, the Public Knowledge Project was founded and began the process of creating the first open-source journal publication system that supported the entire editorial workflow. ${ }^{3}$ The Open Journal Systems (OJS) software is available free of charge and can be installed wherever the prerequisite technical requirements are met. ${ }^{4}$ This has made it attractive to new publishing programs in libraries all over the world, allowing them to put scarce resources into producing high quality content instead of paying a commercial firm for journal hosting.

Business models of these library journal programs vary, but almost all provide basic journal hosting services free of charge. A few library publishing programs offer additional tiers of fee-based services that further enhance the publication process, such as website customization, graphic design, copyediting, and promotional services. However, many editors do not have outside funding and, instead, collaborate with other scholars who can provide these services free of charge. These collaborations are actually helpful to a new cross-disciplinary journal, since it creates a pool of researchers that are invested in the success of a journal and will be more likely to serve as peer reviewers and to promote the journal throughout their academic networks.

\section{Barriers to Publishing Cross- Disciplinary Research}

Financial Considerations

The publication of new cross-disciplinary journals is less appealing to commercial publishers because these journals may initially have a smaller audience and may never be commercially viable. Conversely, some commercial publishers may establish cross-disciplinary journals, only to cease publishing issues when they are no longer profitable. For example, the journals program at the University of Kansas (KU) Libraries was approached by a member of the KU faculty asking the program to take over the publication of an important journal in his field that 
was no longer going to be published by a commercial publisher. With the full assistance of the publisher, the journal moved to our OJS system and continues to publish high-quality peer-reviewed research in its new home.

Article publication fees charged by some commercial open access journals to finance journal costs may be a barrier to authors of cross-disciplinary research who do not have outside funding available to them. Lack of outside funding can also be a barrier to research in the humanities or when publishing with international partners that might be unable to obtain funding.

\section{Disciplinary Considerations}

New forms of cross-disciplinary research submitted to traditional journals in the field are often rejected because their cross-disciplinary approach does not fit within the stated scope of the journals.

Also, in order for the research in new cross-disciplinary journals to be taken seriously, the editors of new cross-disciplinary journals must be well-respected members of their fields that are willing to risk failure if the journal does not find an audience. Finding scholars that can afford to take that risk may be difficult; untenured faculty who are still establishing their scholarly reputations often prefer to do editorial work for traditional journals in their discipline, because those are the positions that are given the most weight by tenure committees. Senior faculty who serve as editors of traditional journals may be reluctant to take a chance on a new cross-disciplinary journal, because failure of the journal may tarnish their scholarly reputation.

\section{Access and visibility}

Commercially published journals are typically kept behind paywalls, where access is by subscription only unless the author has paid the publisher to ensure that the research will be openly available. This limits the audience for that research to those readers, or their institutions, that are able to pay for access.

In addition, as journal prices rise and library budgets decline in purchasing power, less-accessed journals may be dropped from library subscription packages, which limits visibility and access to research in those journals. Interlibrary loan is sometimes used to provide access from the collection of another institution, but those services are not available to all readers.

\section{How Library Journal Programs Support Interdisciplinary Research \\ Enhanced Visibility}

Journal publishing in libraries adheres to standards such as the Open Archives Initiative Protocol for Metadata Harvesting (OAI-PMH $)^{5}$ that exposes journal content to the web search engines that make it available to a worldwide audience.

In addition to making content widely discoverable, library journal programs encourage journals to follow best practices in licensing open materials, such as the use of Creative Commons licenses ${ }^{6}$ that make it clear to the reader how the research can be re-used without asking for permission from the copyright holders.

The visibility of journals hosted by library publishing programs often results in more submissions to the journal, as scholars interested in cross-disciplinary research discover these outlets for publication. Another benefit of visibility is the possibilities for new research partnerships for authors as other scholars with similar interests find the research.

\section{Lower Cost, Lower Risk}

Publishing through library publishing programs is cost effective for the journal, since the lack of a profit motiva- 
tion means that the costs of the library publishing infrastructure is subsidized so that journal hosting can be provided to journals free of charge. Traditional library values emphasizing the preservation and dissemination of knowledge extend into their journal programs, which often provide for the long-term preservation of journal content.

Open access publishing eliminates the need for the journal to allocate resources to subscription management, including reminders, renewals, tracking of payments, etc. Some smaller scholarly societies that publish journals find themselves in the predicament of paying more to manage subscriptions than the subscriptions provide in revenue. By moving journals to a library publishing program and making them open access, a scholarly society not only saves those costs, but also provides a wider outlet for the research of its membership.

Once the publishing infrastructure is in place, there is very little cost to the library journals program to publish a new cross-disciplinary journal. This lowers the financial risk to the publisher if a new journal fails to find an audience and ceases publication. Since library publishers have less to lose if they take a chance on a new journal, journals are not pressured to publish a minimum number of articles per issue or to find an audience in a short amount of time. This gives library-published journals the freedom to experiment with new forms and combinations of scholarship that may not be commercially viable.

Existing print-only journals can eliminate substantial printing costs by moving to an online-only model on a library publishing platform. This has the added benefit of making the research in the journal much more visible to an audience beyond its previous subscribers.

\section{Library Expertise}

Journals published by libraries benefit from existing library expertise in scholarly publishing, project management, experience collaborating with peers to manage scarce resources, copyright, digital preservation, and adherence to standards for the effective promotion of online research.

Libraries are also experts at building communities of interest. For example, the University of Kansas Libraries' journal publishing program periodically hosts Editor Forums in the Libraries where faculty editors from all disciplines can meet to talk about the challenges of journal editing with other editors. An email discussion list allows KU editors to continue the conversations and ask for advice from other editors if a situation arises between meetings. This community of editors provides support to new editors and allows experienced editors to share their extensive knowledge of scholarly publishing.

\section{Visibility is the Key to Success}

The visibility and discoverability of journals in library publishing programs results in a large number of downloads of journal content. For example, articles in the 24 journals hosted by the University of Kansas Libraries on the OJS platform ${ }^{7}$ were downloaded over 2.7 million times in 2019. See Figure 1 for a list of these journals, as well as those additional journals that are available through KU ScholarWorks, KU's online institutional repository.

\section{Common Strategies for Visibility Open Access}

- Make as much article content as possible publicly available without a paywall to encourage use and citation.

- Add all older issues and articles whenever possible when publishing an established print journal 


\section{Journals and Serials}

KU Libraries provides journal editors with the technical infrastructure to publish their journals on either of two platforms: KU ScholarWorks, KU's institutional repository, which makes journals visible to a wide audience and assures their long term preservation and Open Journal Systems (OJS), which makes journals visible and assures their preservation, but also supports the entire editorial management workflow, including article submission, multiple rounds of peer-review, and indexing.

- American Studies (OJS)

- Auslegung: A journal of philosophy (OJS)

- Biodiversity Informatics (OJS)

- Center for East Asian Studies Publication Series (KU ScholarWorks)

- Chimères (OJS)

- Digital Treatise (OJS)

- $\quad$ Focus on Exceptional Children (OJS)

- Folklorica: Journal of the Slavic and East European Folklore Association (OJS)

- Human Communication \& Technology (OJS)

- $\quad$ IALLT Journal of Language Learning Technologies (OJS)

- Indigenous Nations Journal (KU ScholarWorks)

- Infrastructure Research Institute Reports (KU ScholarWorks)

- Issues in Language Instruction (OJS)

- Journal of Amateur Sport (OJS)

- Journal of Copyright in Education \& Librarianship (OJS)

- Journal of Dramatic Theory and Criticism (OJS)

- Journal of Intercollegiate Sport (OJS)

- Journal of Melittology (OJS)

- Journal of Montessori Research (OJS)

- Journal of Russian American Studies (OJS)

- Journal of Undergraduate Research (KU ScholarWorks)

- Kansas Law Review (KU ScholarWorks)

- Kansas Journal of Medicine (OJS)

- $\quad$ KU Field Methods in Linguistic Description (KU ScholarWorks)

- Latin American Theatre Review (OJS)

- Merrill Series on The Research Mission of Public Universities (OJS)

- Midcontinent Geoscience (OJS)

- Novitates Paleoentomologicae(OJS)

- Scientific Papers of the University of Kansas Museum of Natural History (KU ScholarWorks)

- Slavia Centralis (KU ScholarWorks)

- Slovene Linguistic Studies (KU ScholarWorks)

- $\quad$ Social Thought and Research (KU ScholarWorks)

- Special Publication of the University of Kansas Museum of Natural History (KU ScholarWorks)

- $\quad$ Treatise Online (OJS)

- Undergraduate Research Journal for the Humanities (OJS)

- University of Kansas Paleontological Contributions (KU ScholarWorks)

Figure 1: Journals supported by the KU Libraries journal publishing program 
online for the first time. The more visible content there is, the more likely that readers will discover the journal.

\section{Make Articles Easier for Search Engines to Find}

Another strategy that can used by library journals programs to enhance visibility is to make article information available through other not-for-profit entities so that internet search engines can find journal content more easily. Here are some examples:

- Register DOIs with Crossref ${ }^{8}$ or DataCite $^{9}$ to provide permanent links to journal articles and, as a byproduct of this process, to make article information more available to search engines.

- Encourage authors to add their Open Researcher and Contributor ID (ORCID) when submitting an article. An ORCID is a unique researcher identification number used to connect research outputs such as articles to a particular researcher. An advantage of using ORCID is not only that researchers with similar names can clearly identify the work that is theirs, but also that granting agencies are starting to use ORCID as an optional way to add faculty publications to grant applications. Rather than typing the information for each publication, integration with ORCID allows the information to be imported directly to the grant application. ${ }^{10}$

- Help journals apply for inclusion in the Directory of Open Access Journals (DOAJ) and, once they are successful, upload article information to DOAJ as it is published. ${ }^{11}$
- Include machine-readable Creative Commons licenses for articles whenever possible to make it clear to readers how the content can be used. Machine-readable Creative Commons licenses also allow search engines to include those articles in results when a user searches for content that is licensed for re-use. ${ }^{12}$

- Follow the best practices in Google Scholar's Inclusion Guidelines for Webmasters ${ }^{13}$ so that Google Scholar indexes the journal articles.

\section{Editors as Partners}

Predatory open access journals that charge authors large fees to publish poorly researched or scholarly research that does not undergo rigorous peer-review have warped many scholars' perceptions of open access publishing as sub-standard. There is a commonly-held belief, possibly nurtured by those that benefit, that only through commercial publishing channels can quality research be published.

However, for all journals, whether published commercially or not, the reputation of the journals are closely tied to the reputation of the editor and editorial team. Indeed, open access journals with respected editorial teams that do not charge author fees have no incentive to publish poor research, as there is no commercial reward for quantity over quality.

Editors can greatly contribute to the success of their cross-disciplinary journals by following a few simple guidelines:

- Journals that are managed by one person trying to do everything are not sustainable and usually cease publication after a few years. Share the burdens of edi- 
torship and ensure continuity of the journal by making sure that there is a group of scholars involved in running the journal, soliciting content, and performing reviews. Including other scholars also brings other perspectives to the journal and helps minimize the risks of publishing in a new area of scholarship.

- Ensure that information on the journal website-e.g., focus and scope, author guidelines, copyright information, and publication agreements-is clear and complete.

- Require abstracts to be submitted with articles. More information on the article's page gives readers incentive to download the article.

- Support all readers by following the World Wide Web Consortium's Web Content Accessibility Guidelines (WCAG) to ensure that the journal website and journal content are accessible. ${ }^{14}$

- Encourage authors to share their articles in their online institutional repositories with links back to the original published content. Since content in institutional repositories is placed higher in search results by Google's search algorithm, this will increase the visibility of your journal.

- Editors should use their existing scholarly and social media networks to promoting the jour- nal. Sending calls for papers, announcements of special issues, and the publication of new issues to a disciplinary discussion list or forum is an excellent way to call attention to a journal. Announcements at conferences are often very successful, too, especially if connected to a presentation at the conference.

- Solicit articles from well-respected scholars that are acquainted with members of the editorial team. A request from a friend is much more likely to be taken seriously by a reputable scholar.

- Invite selected authors from the journal to be reviewers for future issues.

- The online guide for editors, $\underline{\mathbf{R e}}$ sources for Editors of Scholarly Journals ${ }^{15}$ is a good starting point for those who are considering starting a journal or who are looking for information about managing an existing journal. For those journals on the OJS platform, the Using Open Journal Systems page can be especially helpful. ${ }^{16}$

\section{Summary}

Library publishing programs are uniquely positioned to help cross-disciplinary journals prosper. For scholars thinking of starting a new journal or for editors of a journal that is looking for a new home, library publishing programs are the ideal partner to help the journal, and its editors, succeed.

\section{References}

1. Chapman, A.L. and David E. Shulenburger. "The State of Research Endeavors: View from the Campus-wide Leadership Level." Merrill Series on The Research Mission of Public Universities (1997): 67-68. https://doi.org/10.17161/merrill.1997.8173

2. Steinmetz, Joseph E. "The Role of Universities in Promoting Scholarly Work in the Emerging Open Access World." Merrill Series on The Research Mission of Public Universities (2018): 1-9. https://doi.org/10.17161/merrill.2018.9120 
3. “History." Public Knowledge Project. Accessed June 16, 2019. https://pkp.sfu.ca/ about/history/.

4. “Download Open Journal Systems." Public Knowledge Project. Accessed June 16, 2019. https://pkp.sfu.ca/ojs/ojs download/

5. "Open Archives Initiative Protocol for Metadata Harvesting." Open Archives Initiative. Accessed June 16, 2019. https://www.openarchives.org/pmh/

6. "CC Licenses and Examples." Creative Commons. Accessed June 16, 2019. https:// creativecommons.org/share-your-work/licensing-examples/

7. "Journals@KU." University of Kansas Libraries. Accessed June 16, 2019. https:// journals.ku.edu

8. "Home." Crossref. Accessed June 16, 2019. https://www.crossref.org/

9. "Home." DataCite. Accessed June 16, 2019. https://datacite.org/

10. “Home." ORCID. Accessed June 16, 2019. https://orcid.org/

11. “DOAJ (Directory of Open Access Journals.)” DOAJ. Accessed June 16, 2019. https:// doaj.org/

12. "Home." Creative Commons. Accessed June 16, 2019. https://creativecommons. org/

13. "Inclusion Guidelines for Webmasters." Google Scholar. Accessed June 16, 2019. https://scholar.google.com/intl/en/scholar/inclusion.html

14. "Web Content Accessibility Guidelines (WCAG) 2.1." World Wide Web Consortium. Accessed June 16, 2019. https://www.w3.org/TR/WCAG21/

15. "Resources for Editors of Scholarly Journals: Getting Started." Digital Publishing Services, University of Kansas Libraries. Accessed June 16, 2019. https://guides.lib. ku.edu/journal_editors

16. "Resources for Editors of Scholarly Journals: Using Open Journal Systems (OJS), version 3.x." Digital Publishing Services, University of Kansas Libraries. Accessed June 16, 2019. https://guides.lib.ku.edu/journal editors/learn ojs3 